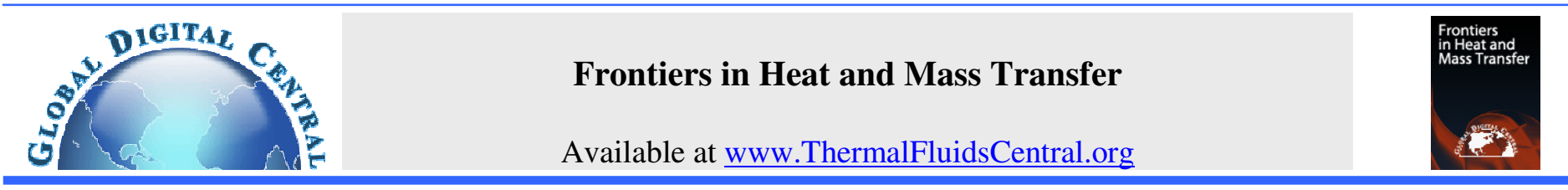

\title{
BOUNDARY LAYER STAGNATION-POINT FLOW OF CASSON FLUID AND HEAT TRANSFER TOWARDS A SHRINKING/STRETCHING SHEET
}

\author{
Krishnendu Bhattacharyya* \\ Department of Mathematics, The University of Burdwan, Burdwan-713104, West Bengal, India
}

\begin{abstract}
The steady boundary layer stagnation-point flow of Casson fluid and heat transfer towards a shrinking/stretching sheet is studied. Appropriate similarity transformations are employed to transform the governing partial differential equations into the self-similar ordinary differential equations and those are then solved numerically using very efficient shooting method. The numerical computations are carried out for several values of parameters involved (especially, velocity ratio parameter and Casson parameter) to know the possibility of similarity solution for the boundary layer stagnation-point flow. It is found that the range of velocity ratio parameter for which similarity solution exists is unaltered for any change in Casson parameter, though the skin friction changes with Casson parameter. Thus, the possibility of similarity solution for Casson fluid flow is same as that of Newtonian fluid flow.
\end{abstract}

Keywords: Boundary layer stagnation-point flow, Casson fluid, heat transfer, shrinking/stretching sheet.

\section{INTRODUCTION}

Derivation of boundary layer equations for the flow and their solutions using similarity transformations is among the most successful idealization in the history of fluid mechanics [Schlichting and Gersten (2000)]. With the help of this boundary layer theory, the flows of various types of fluids (Newtonian and different non-Newtonian fluids) have been successfully mathematically modeled and the derived equations are solved. The obtained results are in excellent agreement with experimental observations. However, many fluids of industrial importance are of non-Newtonian type. It is now generally recognized that, in real industrial applications, non-Newtonian fluids are more appropriate than Newtonian fluids, due to their applications in petroleum drilling, polymer engineering, certain separation processes, manufacturing of foods and paper and some other industrial processes [Mustafa et al. (2011), Cortell (2008)]. Therefore, the analysis of flow dynamics of non-Newtonian fluids is extremely important.

For non-Newtonian fluids, various types of nonlinear relationship between stress and the rate of strain are observed and it is difficult to express all those properties of several non-Newtonian fluids in a single constitutive equation. Consequently, several non-Newtonian fluid models [Fox et al. (1969), Wilkinson (1970), Djukic (1974), Rajagopal (1980), Rajagopal and Gupta (1981), Dorier and Tichy (1992), Zhou and Gao (2007), Cui et al. (2010) and Bhattacharyya and Layek (2011a)] have been proposed depending on various physical characters. Casson fluid is one of such non-Newtonian fluids, which behaves like an elastic solid and for this fluid, a yield shear stress exists in the constitutive equation. Fredrickson (1964) investigated the steady flow of a Casson fluid in a tube. Mustafa et al. (2011) studied the unsteady boundary layer flow and heat transfer of a Casson fluid over a moving flat plate with a parallel free stream using homotopy analysis method (HAM).
On the other hand, boundary layer flows of non-Newtonian fluids caused by a stretching sheet have vast applications in several manufacturing processes such as extrusion of molten polymers through a slit die for the production of plastic sheets, hot rolling, wire and fiber coating, processing of food stuffs, metal spinning, glass-fiber production and paper production [Hayat et al. (2008a)]. During the processes, the rate of cooling has an important bearing on the properties of the final product. Hence, the quality of the final product depends on the rate of heat transfer from the stretching surface. The viscous fluid flow due to a stretching flat sheet was first investigated by Crane (1970). The pioneering work of Crane was extended by Rajagopal et al. (1984) by taking viscoelastic fluid and also Siddappa and Abel (1985) discussed some other important aspects of flow of non-Newtonian fluid over stretching sheet. Sankara and Watson (1985) studied micropolar fluid flow over a stretching sheet. Troy et al. (1987) established the uniqueness of solution of the flow of second order fluid over a stretching sheet. Andersson and Dandapat (1991) reported the flow behaviour of a non-Newtonian power-law fluid over a stretching sheet.

Hiemenz (1911) first reported the stagnation point flow towards a flat plate. It is worthwhile to note that the stagnation flow appears whenever the flow impinges to any solid object and the local fluid velocity at a point (called the stagnation-point) is zero. Chiam (1994) extended the works of Hiemenz (1911) replaced the solid body a stretching sheet with equal stretching and straining velocities and he was unable to obtain any boundary layer near the sheet. Whereas, Mahapatra and Gupta (2001) re-investigated the stagnation-point flow towards a stretching sheet considering different stretching and straining velocities and they found two different kinds of boundary layers near the sheet depending on the ratio of the stretching and straining constants. Some other important aspects of stagnation-point flow of Newtonian fluid are discussed by Nazar et al. (2004), Layek et al. (2007), Nadeem et al. (2010), Bhattacharyya et al. (2011a,2012a,b) and 
Salem and Fathy (2012). Mahapatra et al. (2009) studied the boundary layer magnetohydrodynamic (MHD) stagnation-point flow of an electrically conducting non-Newtonian power-law fluid towards a stretching surface. Van Gorder and Vajravelu (2010) explained the hydromagnetic stagnation point flow of a second grade fluid over a stretching sheet. Recently, Hayat et al. (2012) analyzed the mixed convection stagnation-point flow of a non-Newtonian Casson fluid over a stretching sheet considering convective boundary conditions.

In contrast, the flow due to a shrinking sheet [Wang (1990)] exhibits quite different behaviour from the forward stretching sheet flow. This shrinking sheet flow is essentially one of backward flows described by Goldstein (1965). The generated vorticity due to shrinking makes the nature of the flow interesting. In their study, Miklavčič and Wang (2006) established the requirement of adequate amount of fluid mass suction through the porous sheet to maintain the steady boundary layer flow of Newtonian fluid due to shrinking of porous flat sheet. Actually, fluid mass suction suppresses the vorticity generated due to shrinking of the sheet, inside the boundary layer. Later, numerous important properties of shrinking sheet flows of Newtonian fluid are discussed by Fang and Zhang (2009), Fang et al. (2009,2010), Bhattacharyya and Pop (2011) and Bhattacharyya (2011a,b,c). Hayat et al. $(2008 \mathrm{~b}, 2010)$ reported the MHD flow and mass transfer of a upperconvected Maxwell fluid over a porous shrinking sheet in presence of chemical reaction and they also obtain an analytic solution of flow of non-Newtonian second grade fluid due to shrinking sheet in a rotating frame. Bhattacharyya et al. (2012c) showed the effects of thermal radiation on micropolar fluid flow and heat transfer on a porous shrinking sheet. The non-Newtonian power-law fluid flow past a permeable shrinking sheet with fluid mass transfer was studied by Fang et al. (2012). Most importantly, Bhattacharyya et al. (2013a,b) recently investigated the boundary layer flow of Casson fluid over a permeable stretching/shrinking sheet without and with magnetic field effect.

The boundary layer stagnation-point flow on a shrinking sheet is interesting for its unusual nature and Wang (2008) illustrated those characters by his study of two-dimensional stagnation point flow of Newtonian fluid towards a shrinking sheet. Later, Bhattacharyya and Layek (2011b) explained the effects of suction/blowing and thermal radiation on boundary layer stagnation-point flow and heat transfer past a shrinking sheet and Bhattacharyya et al. (2011b) reported the slip effects on steady stagnation-point flow and heat transfer over a shrinking sheet. The influence of external magnetic field on stagnationpoint flow over a shrinking sheet was described by Mahapatra et al. (2011) and Lok et al. (2011). Fan et al. (2010) obtained analytic homotopy solutions of unsteady stagnation-point flow and heat transfer over a shrinking sheet, where as, Bhattacharyya $(2011 \mathrm{~d}, 2013)$ found the numerical solutions of that flow problem. In addition, Bhattacharyya (2011e), Bachok et al. (2011), Rosali et al. (2011), Bhattacharyya and Vajravelu (2012), Bhattacharyya et al. (2012d), Van Gorder et al. (2012) and Mahapatra et al. (2012) and Mahapatra and Nandi (2013) explored various important aspects of stagnation-point flow due to shrinking sheet for Newtonian fluid. From literature, it can be found that not much attention is given to the stagnation-point flow of nonNewtonian fluid on shrinking sheet. Ishak et al. (2010) and Yacob et al. (2011) discussed the steady boundary layer stagnation-point flow of micropolar fluid past a stretching/shrinking sheet. Nazar et al. (2011) presented the stagnation-point flow and heat transfer towards a shrinking sheet in a nanofluid. Khan et al. (2012) proposed a mathematical model for the unsteady stagnation point flow of a linear viscoelastic fluid bounded by a stretching/shrinking sheet.

The increasing use of several non-Newtonian fluids in processing industries has given a strong motivation to understand their behavior in several transport processes. Therefore, in this investigation, the steady boundary layer stagnation-point flow of an incompressible Casson fluid and heat transfer towards a shrinking/stretching sheet are studied. The governing partial differential equations are converted into the nonlinear ordinary differential equations using the suitable similarity transformations. The transformed self-similar ODEs are solved by shooting method, an efficient numerical method [Mahapatra and Nandi (2013), Ishak et al. (2010), Yacob et al. (2011)] for solving boundary value problem. Then a graphical analysis is presented to show the existence and uniqueness of solution and to elaborately discuss the characters of the flow and heat transfer for the variation of physical parameters.

\section{FLOW ANALYSIS}

Consider the steady two-dimensional stagnation-point flow of incompressible Casson fluid induced by a shrinking/stretching sheet located at $y=0$, the flow being confined in $y>0$ (Fig. 1). It is assumed also that the rheological equation of state for an isotropic and incompressible flow of a Casson fluid can be written as [Nakamura and Sawada (1988), Mustafa et al. (2011), Bhattacharyya et al. (2013a)]:

$\tau_{i j}= \begin{cases}\left(\mu_{B}+p_{y} / \sqrt{2 \pi}\right) 2 e_{i j}, & \pi>\pi_{c} \\ \left(\mu_{B}+p_{y} / \sqrt{2 \pi_{c}}\right) 2 e_{i j}, & \pi<\pi_{c},\end{cases}$

where $\mu_{B}$ is plastic dynamic viscosity of the non-Newtonian fluid, $p_{y}$ is the yield stress of fluid, $\pi$ is the product of the component of deformation rate with itself, namely, $\pi=e_{i j} e_{i j}, e_{i j}$ is the $(i, j)$-th component of the deformation rate and $\pi_{c}$ is critical value of $\pi$ based on nonNewtonian model.

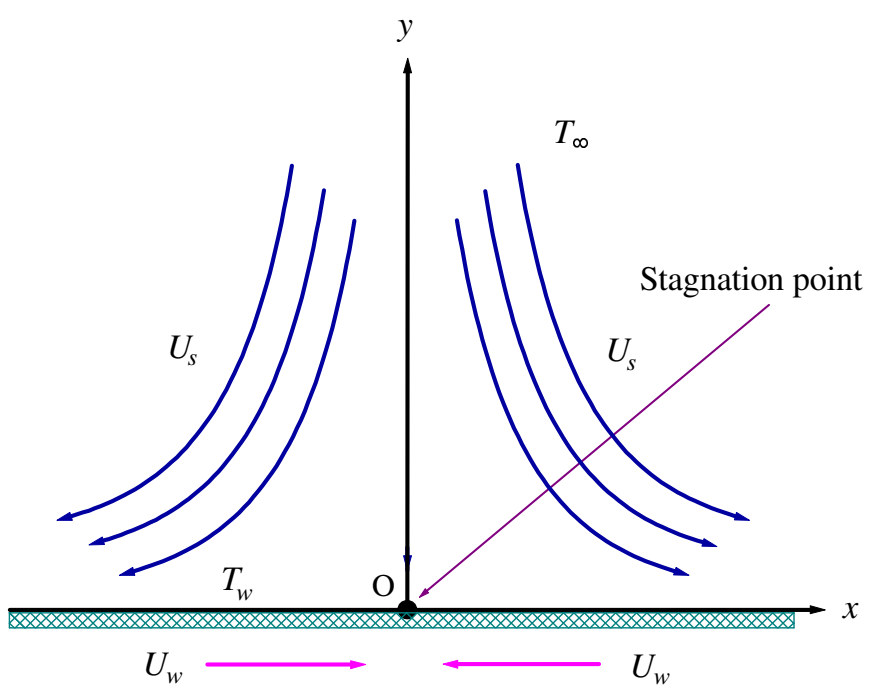

Fig. 1 Physical sketch of the problem.

Under above conditions the boundary layer equations for steady stagnation-point flow towards a shrinking/stretching sheet can be written as:

$\frac{\partial u}{\partial x}+\frac{\partial v}{\partial y}=0$

$u \frac{\partial u}{\partial x}+v \frac{\partial u}{\partial y}=U_{s} \frac{d U_{s}}{d x}+v\left(1+\frac{1}{\beta}\right) \frac{\partial^{2} u}{\partial y^{2}}$,

where $u$ and $v$ are the velocity components in $x$ and $y$ directions respectively, $x$ is distance along the sheet, $y$ is distance perpendicular to the sheet, $U_{s}=a x$ is the straining velocity of the stagnation-point flow with $a(>0)$ being the straining constant, $v$ is the kinematic fluid viscosity and $\beta=\mu_{B} \sqrt{2 \pi_{c}} / p_{y}$ is the non-Newtonian or Casson parameter.

The boundary conditions for the velocity components are $u=U_{w}, v=0$ at $y=0 ; u \rightarrow U_{s}$ as $y \rightarrow \infty$,

where $U_{w}=c x$ is shrinking/stretching velocity of the sheet with $c$ being the shrinking/stretching constant and $c<0$ corresponds to shrinking and $c>0$ corresponds to stretching. 
Table 1 Values of $f^{\prime \prime}(0)$ for several values of $c / a$ for $\beta=\infty$ (Newtonian fluid case) for stretching sheet.

\begin{tabular}{|l|c|c|c|}
\hline \multicolumn{1}{|c|}{$c / a$} & Present study & Wang (2008) & Ishak et al. (2010) \\
\hline 0 & 1.2325878 & 1.232588 & 1.232588 \\
0.1 & 1.1465608 & 1.14656 & 1.146561 \\
0.2 & 1.0511299 & 1.05113 & 1.051130 \\
0.5 & 0.7132951 & 0.71330 & 0.713295 \\
1 & 0 & 0 & 0 \\
\hline
\end{tabular}

Table 2 Values of $f^{\prime \prime}(0)$ for several values of $c / a$ for $\beta=\infty$ (Newtonian fluid case) for shrinking sheet.

\begin{tabular}{|c|c|c|c|c|c|c|}
\hline \multirow[b]{2}{*}{$c / a$} & \multicolumn{2}{|c|}{ Present study } & \multicolumn{2}{|c|}{ Wang (2008) } & \multicolumn{2}{|c|}{ Ishak et al. (2010) } \\
\hline & $\begin{array}{c}\text { First } \\
\text { solution }\end{array}$ & $\begin{array}{l}\text { Second } \\
\text { solution }\end{array}$ & $\begin{array}{c}\text { First } \\
\text { solution }\end{array}$ & $\begin{array}{l}\text { Second } \\
\text { solution }\end{array}$ & $\begin{array}{c}\text { First } \\
\text { solution }\end{array}$ & $\begin{array}{c}\text { Second } \\
\text { solution }\end{array}$ \\
\hline-0.25 & & & & & & \\
\hline-0.5 & 1.4022405 & & 1.4022 & & 1.402241 & \\
\hline-0.75 & 1.4956697 & & 1.49567 & & 1.495670 & \\
\hline-1 & 1.4892981 & & 1.48930 & & 1.489298 & \\
\hline-1.1 & 1.3288169 & 0 & 1.32882 & 0 & 1.328817 & 0 \\
\hline-1.15 & 1.1866806 & 0.0492286 & & & 1.186681 & 0.049229 \\
\hline-1.2 & 1.0822316 & 0.1167023 & 1.0822 & 0.116702 & 1.082231 & 0.116702 \\
\hline-1.24 & 0.9324728 & 0.2336491 & & & 0.932474 & 0.233650 \\
\hline - & 0.7066020 & 0.4356712 & & & & \\
\hline 1.2465 & 0.5842915 & 0.5542856 & 0.55430 & & 0.584295 & 0.554283 \\
\hline- & 0.5745268 & 0.5639987 & & & & \\
\hline & & & & & & \\
\hline
\end{tabular}

The following relations for $u$ and $v$ are introduced:

$u=\frac{\partial \psi}{\partial y}$ and $v=-\frac{\partial \psi}{\partial x}$,

where $\psi$ is the stream function.

For relations in (5), the equation (2) is satisfied automatically and the equation (3) takes the following form:

$\frac{\partial \psi}{\partial y} \frac{\partial^{2} \psi}{\partial x \partial y}-\frac{\partial \psi}{\partial x} \frac{\partial^{2} \psi}{\partial y^{2}}=U_{s} \frac{d U_{s}}{d x}+v(1+1 / \beta) \frac{\partial^{3} \psi}{\partial y^{3}}$.

Also, the boundary conditions in (4) reduce to

$\frac{\partial \psi}{\partial y}=U_{w}, \frac{\partial \psi}{\partial x}=0$ at $y=0 ; \frac{\partial \psi}{\partial y} \rightarrow U_{s}$ as $y \rightarrow \infty$.

The dimensionless variable for the stream function is introduced as:

$\psi=\sqrt{a v} x f(\eta)$,

where the similarity variable $\eta$ is given by $\eta=y \sqrt{a / v}$.

Using the relation (8) and the similarity variable, the equation (6) finally takes following self-similar form:

$(1+1 / \beta) f^{\prime \prime \prime}+f f^{\prime \prime}-f^{\prime 2}+1=0$,

where primes denote differentiation with respect to $\eta$.

The boundary conditions reduce to

$f(\eta)=0, f^{\prime}(\eta)=c / a$ at $\eta=0 ; f^{\prime}(\eta) \rightarrow 1$ as $\eta \rightarrow \infty$,

where $c / a$ is the velocity ratio parameter.

\section{HEAT TRANSFER}

For the temperature distribution in the flow field, the governing energy equation can be written as:

$u \frac{\partial T}{\partial x}+v \frac{\partial T}{\partial y}=\frac{\kappa}{\rho c_{p}} \frac{\partial^{2} T}{\partial y^{2}}$,

where $T$ is the temperature, $\kappa$ is the thermal conductivity, $\rho$ is the fluid density and $c_{p}$ is the specific heat.

The appropriate boundary conditions are

$T=T_{w}$ at $y=0 ; T \rightarrow T_{\infty}$ as $y \rightarrow \infty$,

where $T_{w}$ is the constant temperature at the sheet and $T_{\infty}$ is the free stream temperature assumed to be constant.

Next, the dimensionless temperature $\theta$ is introduced as:
$\theta(\eta)=\frac{T-T_{\infty}}{T_{w}-T_{\infty}}$.

Using (8), (13) and the similarity variable, the equation (11) reduces to $\theta^{\prime \prime}+\operatorname{Pr} f \theta^{\prime}=0$

where primes denote differentiation with respect to $\eta$ and $\operatorname{Pr}=c_{p} \mu / \kappa$ is the Prandtl number.

The boundary conditions for $\theta$ are obtained from (12) as:

$\theta(\eta)=1$ at $\eta=0 ; \theta(\eta) \rightarrow 0$ as $\eta \rightarrow \infty$.

\section{NUMERICAL METHOD FOR SOLUTION}

The self-similar equations (9) and (14) along with boundary conditions (10) and (15) are solved using shooting method [Bhattacharyya et al. (2011c,d) and Bhattacharyya (2012)] by converting them to an initial value problem (IVP). In this method, it is necessary to choose a suitable finite value of $\eta \rightarrow \infty$, say $\eta_{\infty}$. The following system is set:

$f^{\prime}=p$,

$p^{\prime}=q$,

$q^{\prime}=\left(p^{2}-f q-1\right) /(1+1 / \beta)$,

$\theta^{\prime}=z$

$z^{\prime}=-\operatorname{Prf} z$

with the boundary conditions

$f(0)=0, p(0)=c / a, \theta(0)=1$.

In order to integrate the IVP (16) and (17) with (18), the values for $q(0)$ i.e. $f^{\prime \prime}(0)$ and $z(0)$ i.e. $\theta^{\prime}(0)$ are required, but no such values are given at the boundary. The suitable guess values for $f^{\prime \prime}(0)$ and $\theta^{\prime}(0)$ are chosen and then integration is carried out. Then the calculated values for $f^{\prime}$ and $\theta$ at $\eta_{\infty}=15$ (say) are compared with the given boundary conditions $f^{\prime}(15)=1$ and $\theta(15)=0$ and the estimated values, $f^{\prime \prime}(0)$ and $\theta^{\prime}(0)$ are adjusted to give a better approximation for the solution. A series of values for $f^{\prime \prime}(0)$ and $\theta^{\prime}(0)$ are taken and the fourth order classical Runge-Kutta method with step-size $\Delta \eta=0.01$ is applied. The above procedure is repeated until the asymptotically converged results within a tolerance level of $10^{-5}$ are obtained.

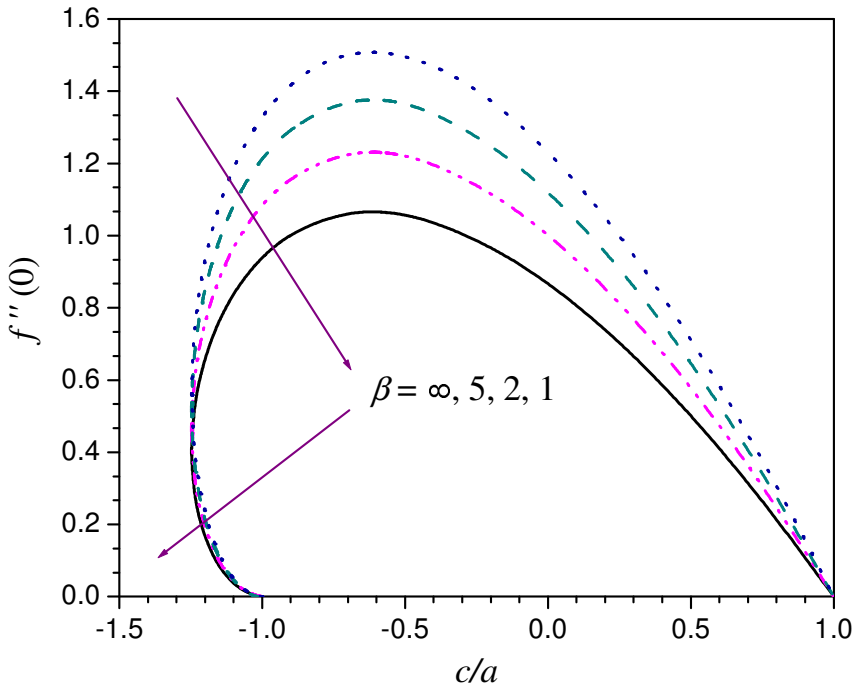

Fig. 2 The values of $f^{\prime \prime}(0)$ vs. $c / a$ for different values of $\beta$.

\section{RESULTS AND DISCUSSIONS}

The numerical computations have been carried out using abovedescribed shooting method for several values of the physical parameters arised in the study: such as, the velocity ratio parameter $(c / a)$, the Casson parameter $(\beta)$ and the Prandtl number $(P r)$. Then acquired results are presented in graphs (Fig. 2-Fig. 14) to explain the existence 
and uniqueness of solution for the flow, as well as, the variations in velocity and temperature fields. Also, to validate the numerical scheme, a comparison of results is made. Table 1 and Table 2 show that the values of $f^{\prime \prime}(0)$ for $\beta=\infty$ (i.e., Newtonian fluid case) are in a favorable agreement with previously published data in the literature by Wang (2008) and Ishak et al. (2010).

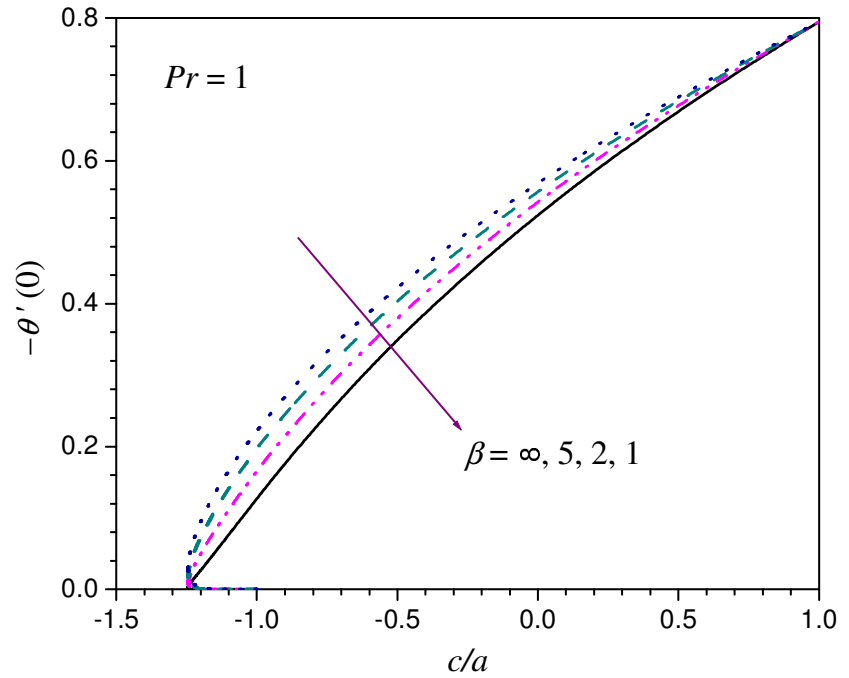

Fig. 3 The values of $-\theta^{\prime}(0)$ vs. $c / a$ for different values of $\beta$.

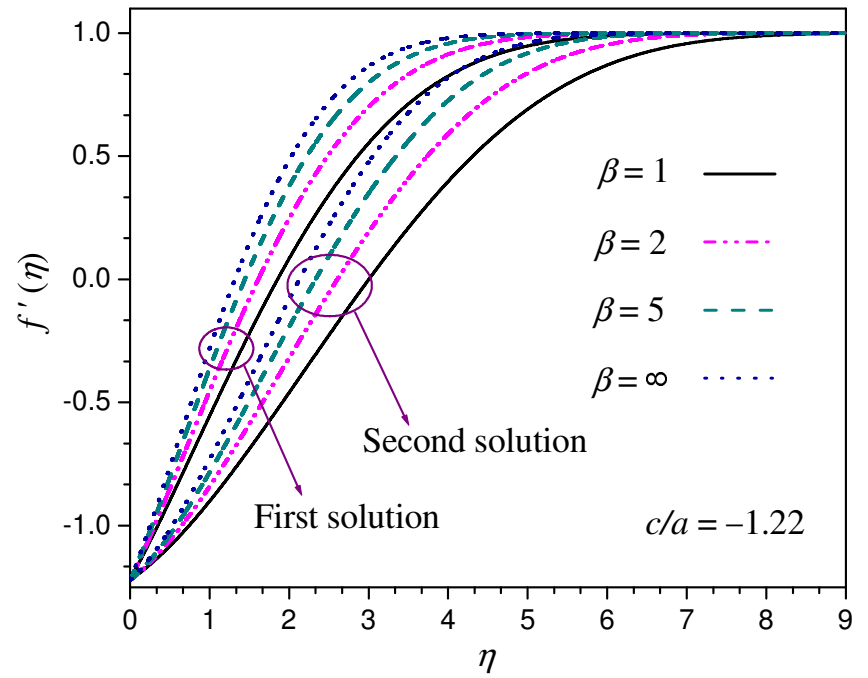

Fig. 4 The effects of $\beta$ on dual velocity profiles $f^{\prime}(\eta)$.

The stagnation-point flow over a shrinking sheet was investigated by Wang (2008) for Newtonian fluid and he found that the self-similar solution of boundary layer flow is possible only if the velocity ratio parameter $c / a$ satisfies the inequality $c / a \geq-1.2465$. In this study, it is obtained that for $\beta=\infty$ i.e., for Newtonian fluid the boundary layer exists if $c / a \geq-1.24657$, which is similar to that of Wang (2008). It has also noted that for $\beta=\infty$ the solution is of dual nature for $-1.24657 \leq c / a \leq 0$, the solution is unique for $c / a>0$ and for $c / a<-1.24657$ no solution is found. Due to decrease in $\beta$ i.e., for Casson fluid, the existence range does not alter and the similarity solution of boundary layer is obtained when $c / a \geq-1.24657$. Therefore, it is worth noting that there is no change occurred in the solution range of $c / a$ due to variation in the Casson parameter $\beta$. For all values of $\beta$, dual solutions exist for $-1.24657 \leq c / a \leq 0$, the solution is unique for $c / a>0$ and no similarity solution is found for $c / a<-1.24657$. Thus, there exists dual self-similar solutions in some situations of shrinking sheet case and for stretching sheet case the solution is always unique. These all phenomena can be observed in Fig. 2 and Fig. 3 of $f^{\prime \prime}(0)$ and $-\theta^{\prime}(0)$ vs. $c / a$, those are related to wall skin friction coefficient and the heat transfer coefficient respectively. Though there is no change in the solution range of $c / a$, but the value of $f^{\prime \prime}(0)$ decreases with decrease of $\beta$ for first and second solutions in dual solutions case and unique solution case. Similar effects is observed for the values of $-\theta^{\prime}(0)$. Hence, for Casson fluid flow over a shrinking sheet near a stagnation-point dual solutions and unique solution are found in the same ranges as that of Newtonian fluid case, but Casson parameter affects the wall skin-friction coefficient as well as the heat transfer coefficient. To know the detailed effects of Casson parameter on the flow, the dimensionless curves related to velocity, temperature and their gradients are plotted.

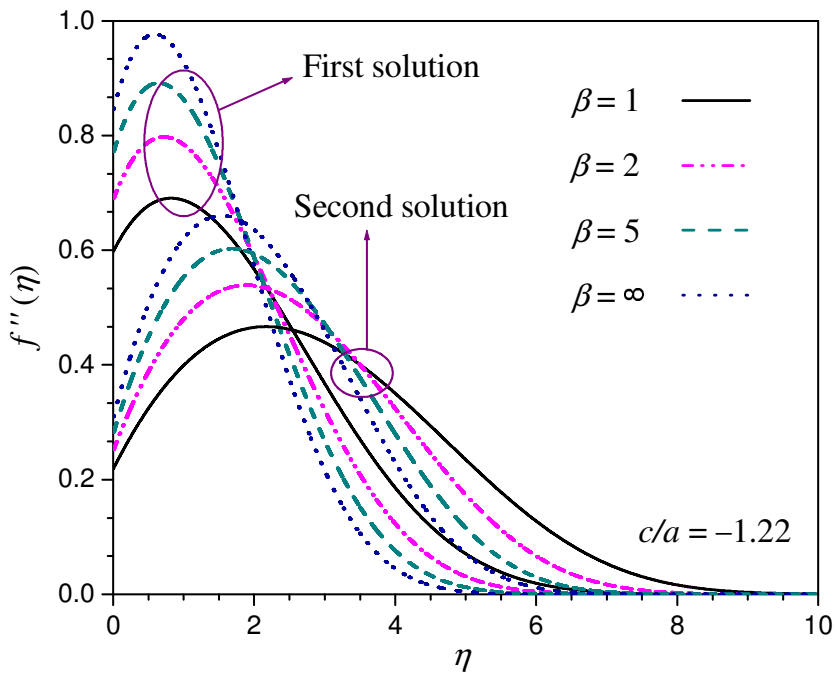

Fig. 5 The effects of $\beta$ on dual velocity gradient profiles $f^{\prime \prime}(\eta)$.

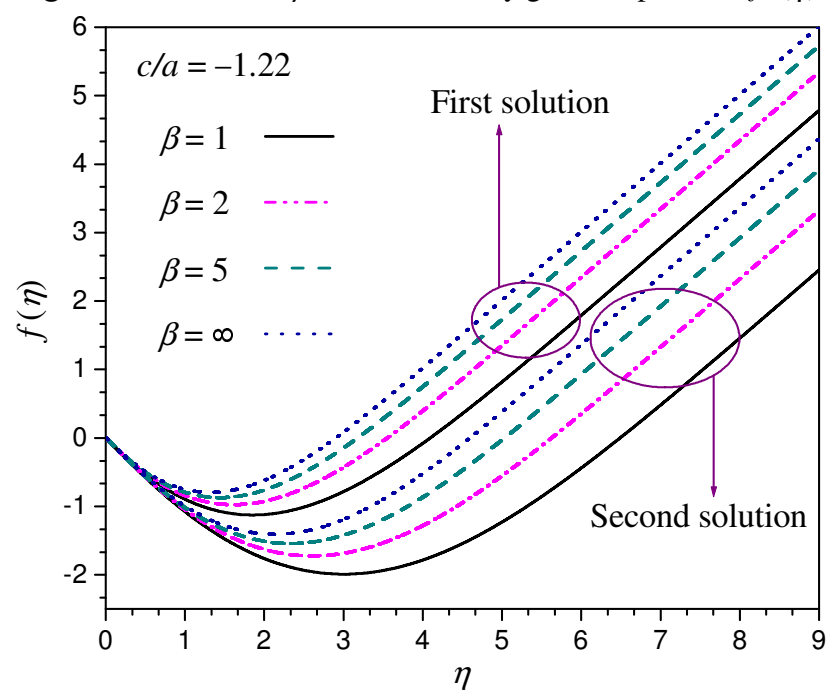

Fig. 6 The effects of $\beta$ on $f(\eta)$.

The dimensionless velocity, velocity gradient, stream function, temperature and temperature gradient are depicted in Fig. 4-Fig. 10 for different values of Casson parameter $\beta$. The velocity at a point decreases with decreasing values of $\beta$ for both solutions in dual solutions (Fig. 4) and also for unique solution (Fig. 9 and Fig. 11). The velocity gradient decreases near the sheet with decreasing $\beta$, but faraway from the sheet it increases (Fig. 5). Also, it is important to note that the decrease in Casson parameter makes the velocity boundary layer thickness larger. Thus, the velocity boundary layer thickness for Casson fluid is larger than that of Newtonian fluid. It happens because of plasticity of Casson fluid. When Casson parameter decreases the plasticity of the fluid increases, which causes the increment in velocity boundary layer thickness. The dimensionless stream function profiles (Fig. 6) show the back flow character of stagnation point flow over a shrinking sheet. The dimensionless temperature increases with the decrease in $\beta$ for all cases, both solutions in dual solutions (Fig. 7) and unique solution (Fig. 10). Similar to the velocity boundary layer, due to 
increase in plasticity of fluid the thermal boundary layer thickness increases with decreasing $\beta$, which can be confirmed from the temperature gradient profiles in Fig. 8. Here also, in dual solutions the boundary layer thickness for second solution is thicker.

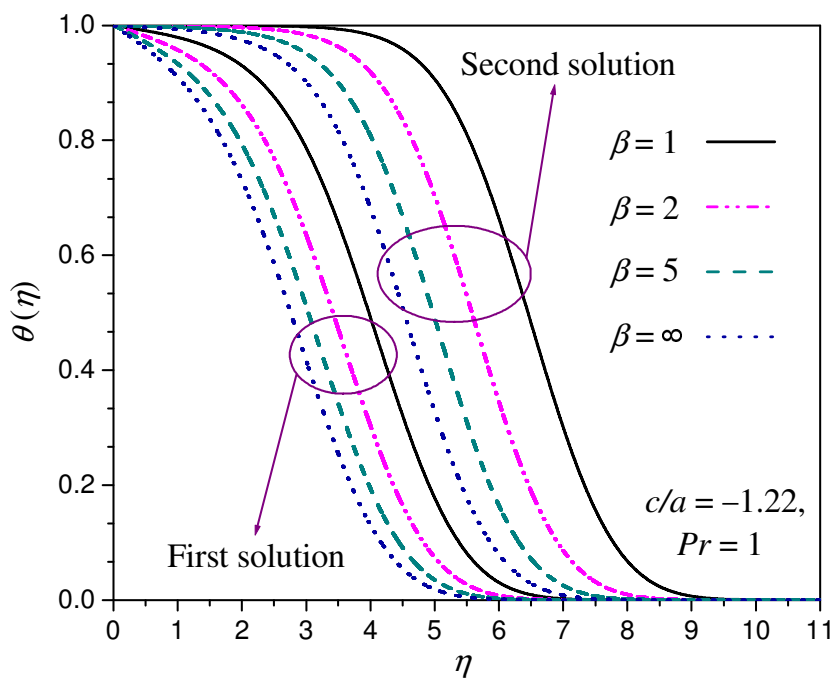

Fig. 7 The effects of $\beta$ on dual temperature profiles $\theta(\eta)$.

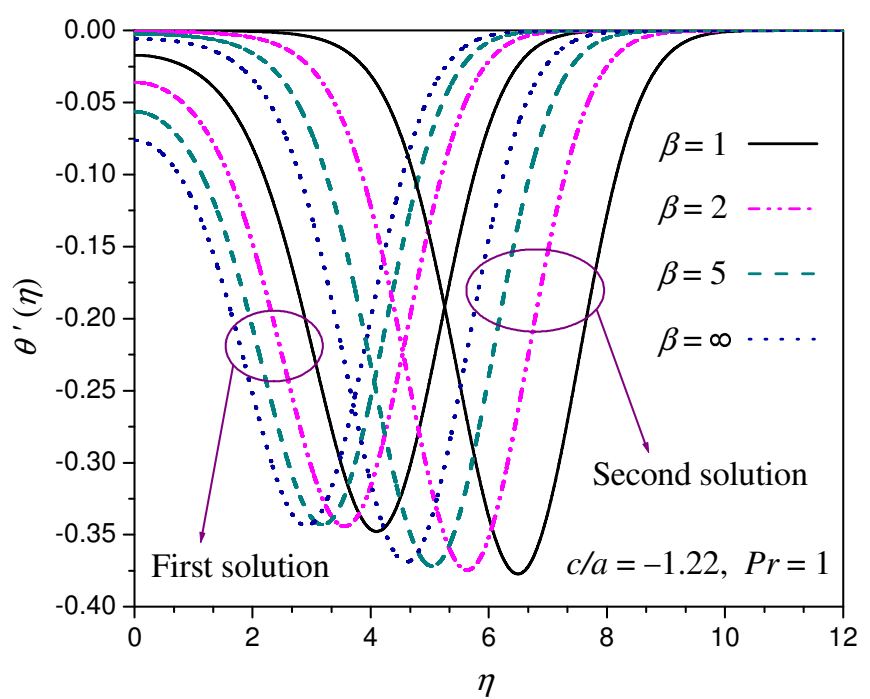

Fig. 8 The effects of $\beta$ on dual temperature gradient profiles $\theta^{\prime}(\eta)$.

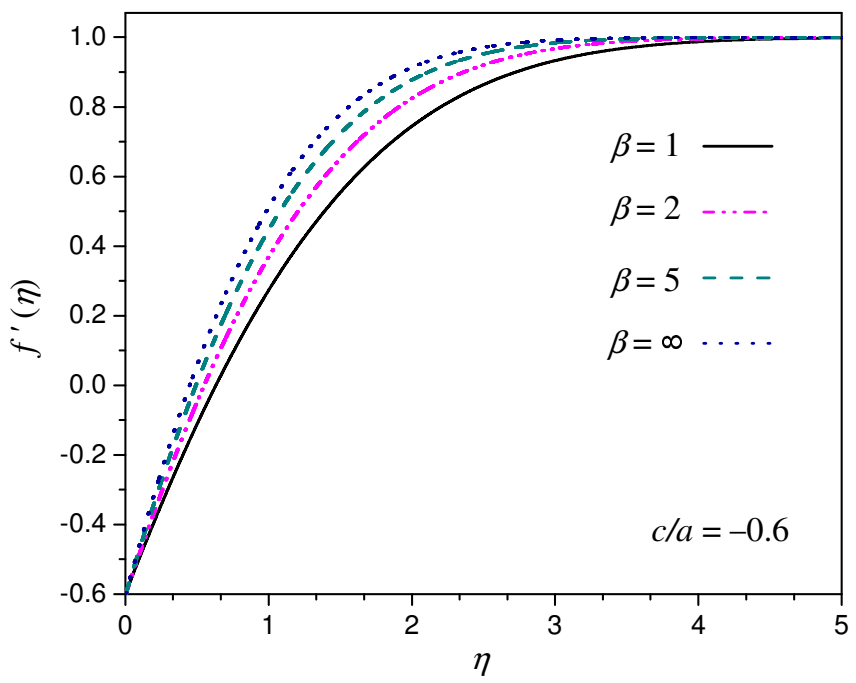

Fig. 9 The effects of $\beta$ on the unique velocity profiles $f^{\prime}(\eta)$ for shrinking sheet.

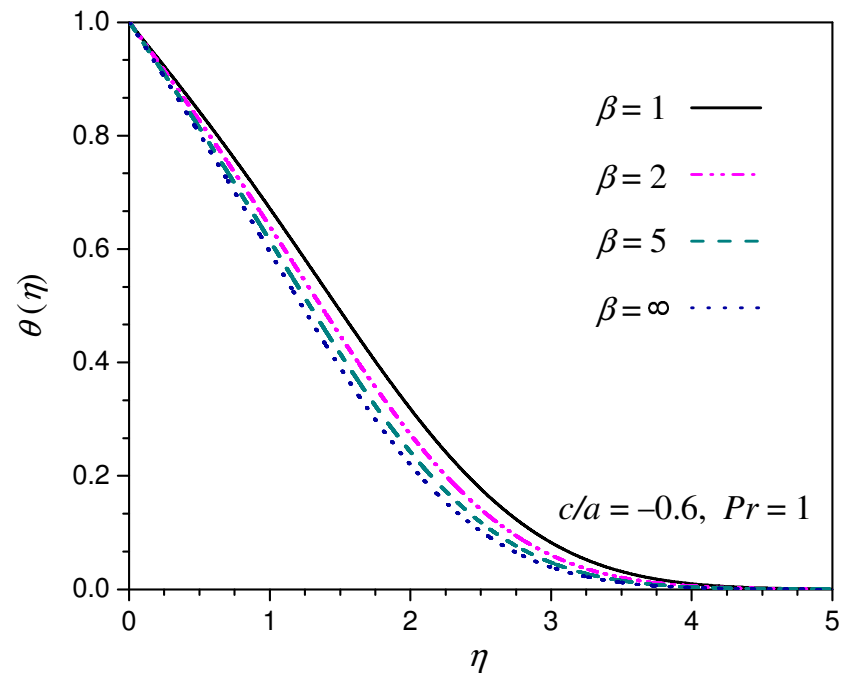

Fig. 10 The effects of $\beta$ on the unique temperature profiles $\theta(\eta)$ for shrinking sheet.

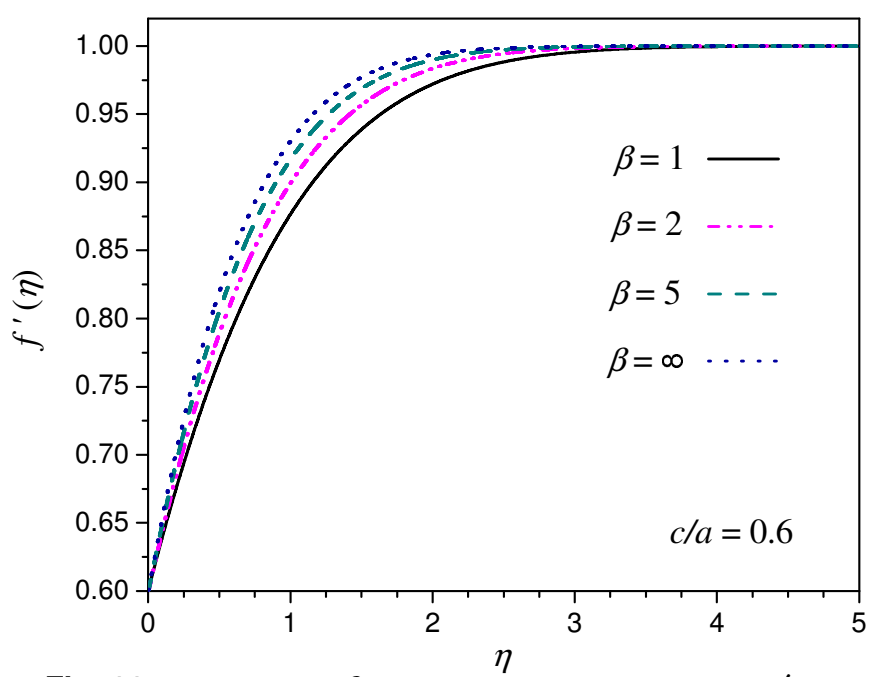

Fig. 11 The effects of $\beta$ on the unique velocity profiles $f^{\prime}(\eta)$ for stretching sheet.

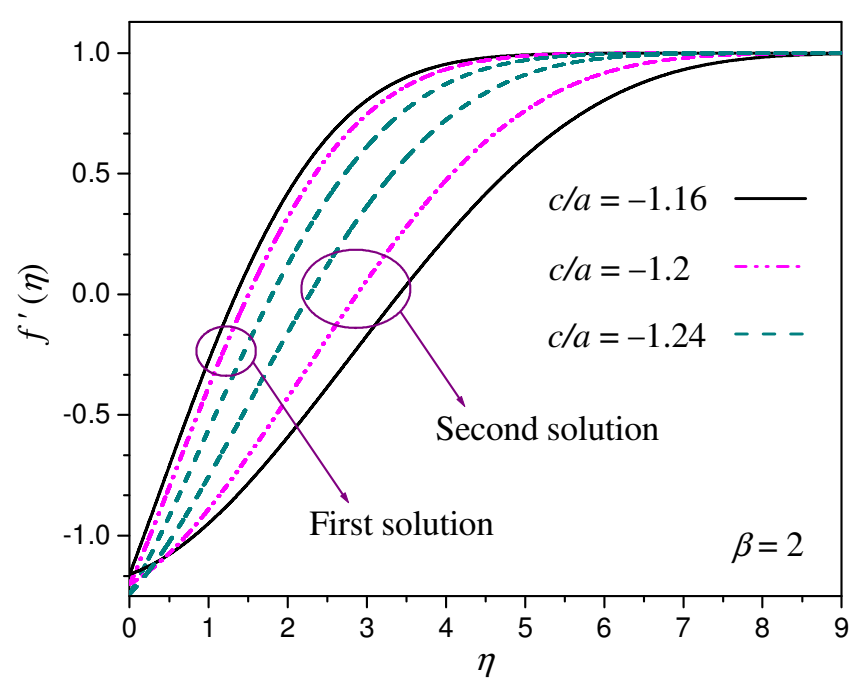

Fig. 12 The effects of $c / a$ on dual velocity profiles $f^{\prime}(\eta)$. 
Next, the focus is concentrated to the effects of the velocity ratio parameter $c / a$ and the Prandtl number $\mathrm{Pr}$ on the velocity and temperature distributions in Casson fluid flow. In Fig. 12 and Fig. 13 the influence of $c / a$ on dual velocity and temperature profiles are presented respectively. Similar to Newtonian fluid case, here for Casson fluid two opposite effects are observed in two solutions. For first solution, boundary layer thicknesses (velocity and thermal) increase with increasing magnitude of $c / a$ and in second solution those decrease. The dual temperature profiles for several values of Prandtl number are demonstrated in Fig. 14. The thermal boundary layer thickness decreases with increasing Prandtl number with a temperature crossing over.

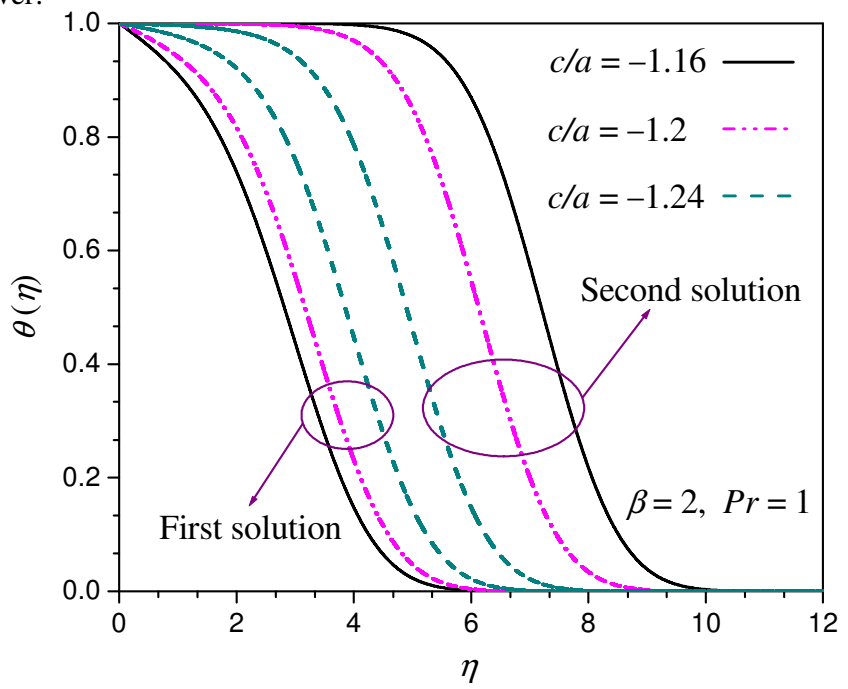

Fig. 13 The effects of $a / c$ on dual temperature profiles $\theta(\eta)$.

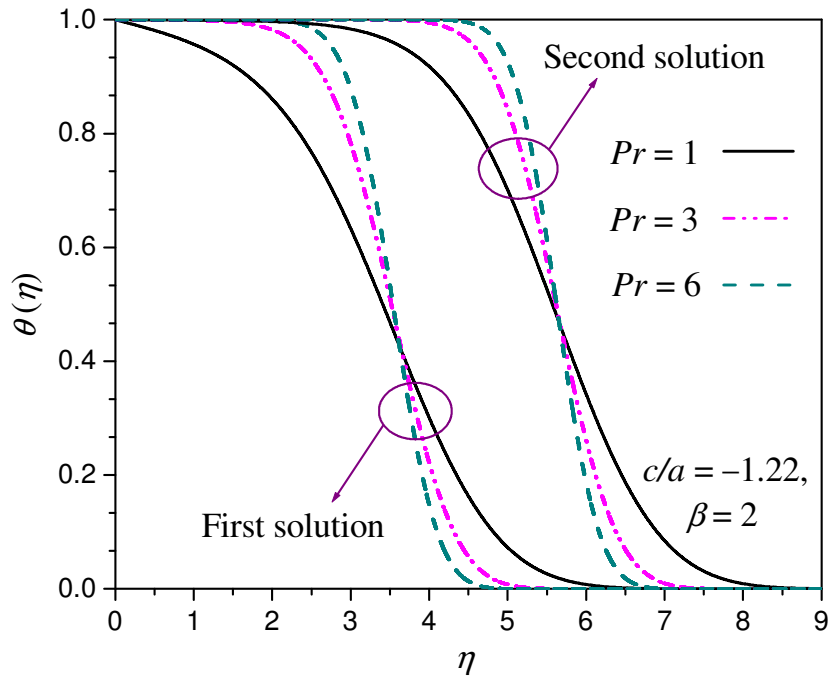

Fig. 14 The effects of $\operatorname{Pr}$ on dual temperature profiles $\theta(\eta)$.

\section{CONCLUSIONS}

The objective of this investigation is to emphasize on similarity solution properties of the boundary layer stagnation-point flow of Casson fluid and heat transfer towards a shrinking/stretching sheet. An analysis of existence and uniqueness of boundary layer self-similar solution of transformed equations is made based on numerical computations using shooting method. The study explores that similar to Newtonian case, the self-similar solution is of dual nature in some situations of shrinking sheet case, for stretching sheet case the solution is always unique. Also, it is found that the velocity and thermal boundary layer thicknesses are larger for Casson fluid than that of Newtonian fluid.

\section{ACKNOWLEDGEMENTS}

The author gratefully acknowledges the financial support of National Board for Higher Mathematics (NBHM), Department of Atomic Energy, Government of india for pursuing this work. The author is also thankful to the referee for his valuable comments and suggestions.

\section{NOMENCLATURE}

a straining constant

c/a velocity ratio parameter

$c \quad$ shrinking/stretching constant

$c_{p} \quad$ specific heat

$f \quad$ dimensionless stream function

$f^{\prime} \quad$ dimensionless velocity

$\mathrm{Pr} \quad$ Prandtl number

$p \quad$ a variable

$p_{y} \quad$ yield stress of fluid

$q \quad$ a variable

$T \quad$ temperature

$T_{w} \quad$ constant temperature at the sheet

$T_{\infty} \quad$ constant free stream temperature

$U_{s} \quad$ straining velocity of the stagnation-point flow

$U_{w} \quad$ shrinking/stretching velocity of the sheet

$u \quad$ velocity component in $x$ direction

$v \quad$ velocity component in $y$ direction

$x \quad$ distance along the sheet

$y \quad$ distance perpendicular to the sheet

$z \quad$ a variable

\section{Greek symbols}

$\beta \quad$ non-Newtonian/Casson parameter

$\eta \quad$ similarity variable

$\eta_{\infty} \quad$ finite value of $\eta$

$\kappa \quad$ thermal conductivity

$\mu_{B} \quad$ plastic dynamic viscosity of the non-Newtonian fluid

$\pi \quad$ product of the component of deformation rate with itself

$\pi_{c} \quad$ critical value of $\pi$

$v \quad$ kinematic fluid viscosity

$\rho \quad$ fluid density

$\psi \quad$ stream function

$\theta \quad$ dimensionless temperature

\section{REFERENCES}

Andersson, H.I., and Dandapat, B.S., 1991, "Flow of a Power-Law Fluid over a Stretching Sheet," Stability Appl. Anal. Continuous Media, 1, 339-347.

Bachok, N., Ishak, A., and Pop, I., 2011, "On The Stagnation-Point Flow Towards a Stretching Sheet with Homogeneous-Heterogeneous Reactions Effects," Commun. Nonlinear Sci. Numer. Simulat., 16, 4296-4302.

http://dx.doi.org/10.1016/J.cnsns.2011.01.008

Bhattacharyya, K., 2011a, "Boundary Layer Flow and Heat Transfer over an Exponentially Shrinking Sheet," Chin. Phys. Lett., 28, 074701. http://dx.doi.org/10.1088/0256-307X/28/7/074701

Bhattacharyya, K., 2011b, "Effects of Radiation and Heat Source/Sink On Unsteady MHD Boundary Layer Flow and Heat Transfer over a Shrinking Sheet with Suction/Injection," Front. Chem. Sci. Eng., 5, 376-384.

http://dx.doi.org/10.1007/S11705-011-1121-0

Bhattacharyya, K., 2011c, "Effects of Heat Source/Sink on MHD Flow and Heat Transfer over a Shrinking Sheet with Mass Suction," Chem. Eng. Res. Bull., 15, 12-17. 


\section{http://dx.doi.org/10.3329/Cerb.V15i1.6524}

Bhattacharyya, K., 2011d, "Dual Solutions in Unsteady StagnationPoint Flow over a Shrinking Sheet," Chin. Phys. Lett., 28, 084702. http://dx.doi.org/10.1088/0256-307X/28/8/084702

Bhattacharyya, K., 2011e, "Dual Solutions in Boundary Layer Stagnation-Point Flow and Mass Transfer with Chemical Reaction past a Stretching/Shrinking Sheet," int. Commun. Heat Mass Transfer, 38, 917-922.

http://dx.doi.org/10.1016/J.Icheatmasstransfer.2011.04.020

Bhattacharyya, K., and Layek, G.C., 2011a, "MHD Boundary Layer Flow of Dilatant Fluid in a Divergent Channel with Suction or Blowing," Chin. Phys. Lett., 28, 084705.

http://dx.doi.org/10.1088/0256-307X/28/8/084705

Bhattacharyya, K., and Layek, G.C., 2011b, "Effects of Suction/Blowing On Steady Boundary Layer Stagnation-Point Flow and Heat Transfer towards a Shrinking Sheet with Thermal Radiation," int. J. Heat Mass Transfer, 54, 302-307.

http://dx.doi.org/10.1016/J.Ijheatmasstransfer.2010.09.043

Bhattacharyya, K., and Pop, I., 2011, "MHD Boundary Layer Flow Due To an Exponentially Shrinking Sheet," Magnetohydrodynamics, 47, 337-344.

Bhattacharyya, K., Mukhopadhyay, S., and Layek, G.C., 2011a, "Slip Effects On Unsteady Boundary Layer Stagnation-Point Flow and Heat Transfer Towards a Stretching Sheet," Chin. Phys. Lett., 28, 094702. http://dx.doi.org/10.1088/0256-307X/28/9/094702

Bhattacharyya, K., Mukhopadhyay, S., and Layek, G.C., 2011b, "Slip Effects On Boundary Layer Stagnation-Point Flow and Heat Transfer Towards a Shrinking Sheet," int. J. Heat Mass Transfer, 54, 308-313. http://dx.doi.org/10.1016/J.Ijheatmasstransfer.2010.09.041

Bhattacharyya, K., Mukhopadhyay, S., and Layek, G.C., 2011c, "MHD Boundary Layer Slip Flow and Heat Transfer over a Flat Plate," Chin. Phys. Lett., 28, 024701.

http://dx.doi.org/10.1088/0256-307X/28/2/024701

Bhattacharyya, K., Mukhopadhyay, S., and Layek, G.C., 2011d, "Steady Boundary Layer Slip Flow and Heat Transfer over a Flat Porous Plate Embedded in a Porous Media," J. Petrol. Sci. Eng., 78, 304-309. http://dx.doi.org/10.1016/J.Petrol.2011.06.009

Bhattacharyya, K., 2012, "Mass Transfer On a Continuous Flat Plate Moving in Parallel Or Reversely To a Free Stream in The Presence of a Chemical Reaction," int. J. Heat Mass Transfer, 55, 3482-3487. http://dx.doi.org/10.1016/J.Ijheatmasstransfer.2012.03.005

Bhattacharyya, K., and Vajravelu, K., 2012, "Stagnation-Point Flow and Heat Transfer over an Exponentially Shrinking Sheet," Commun. Nonlinear Sci. Numer. Simulat., 17, 2728-2734. http://dx.doi.org/10.1016/J.Cnsns.2011.11.011

Bhattacharyya, K., Mukhopadhyay, S., and Layek, G.C., 2012a, "Reactive Solute Transfer in Magnetohydrodynamic Boundary Layer Stagnation-Point Flow over a Stretching Sheet with Suction/Blowing," Chem. Eng. Commun., 199, 368-383.

http://dx.doi.org/10.1080/00986445.2011.592444

Bhattacharyya, K., Mukhopadhyay, S., and Layek, G.C., 2012b, "Effects of Partial Slip On Boundary Layer Stagnation Slip Flow and Heat Transfer Towards a Stretching Sheet with Temperature Dependent Fluid Viscosity," Acta Tech., 57, 183-195.

Bhattacharyya, K., Mukhopadhyay, S., Layek, G.C., and Pop, I., 2012c, "Effects of Thermal Radiation On Micropolar Fluid Flow and Heat Transfer over a Porous Shrinking Sheet," Int. J. Heat Mass Transfer, 55, 2945-2952.

http://dx.doi.org/10.1016/J.Ijheatmasstransfer.2012.01.051
Bhattacharyya, K., arif, M.G., ali, Pk,W., 2012d, "MHD Boundary Layer Stagnation-Point Flow and Mass Transfer over a Permeable Shrinking Sheet with Suction/Blowing and Chemical Reaction," Acta Tech., 57, 1-15.

Bhattacharyya, K., 2013, "Heat Transfer in Unsteady Boundary Layer Stagnation-Point Flow towards a Shrinking Sheet," Ain Shams Eng. J., 4, 259-264.

http://dx.doi.org/10.1016/J.Asej.2012.07.002

Bhattacharyya, K., Hayat, T., and alsaedi, A., 2013a, "Exact Solution For Boundary Layer Flow of Casson Fluid over a Permeable Stretching/Shrinking Sheet," Z. Angew. Math. Mech., http://dx.doi.org/10.1002/Zamm.201200031

Bhattacharyya, K., Hayat, T., and alsaedi, A., 2013b, "Analytic Solution For Magnetohydrodynamic Boundary Layer Flow of Casson Fluid over a Stretching/Shrinking Sheet with Wall Mass Transfer," Chin. Phys. B, 22, 024702.

http://dx.doi.org/10.1088/1674-1056/22/2/024702

Chiam, T.C., 1994, "Stagnation-Point Flow towards a Stretching Plate," J. Phys. Soc. Jpn., 63, 2443-2444.

http://dx.doi.org/10.1143/JPSJ.63.2443

Cortell, R., 2008, "Analysing Flow and Heat Transfer of a Viscoelastic Fluid over a Semi-Infinite Horizontal Moving Flat Plate," Int. J. NonLinear Mech., 43, 772-778.

http://dx.doi.org/10.1016/J.Ijnonlinmec.2008.04.006

Crane, L.J., 1970, "Flow Past a Stretching Plate," Z. Angew. Math. Phys., 21, 645-647.

http://dx.doi.org/10.1007/BF01587695

Cui, Z.-W., Liu, J.-X., Yao, G.-J., and Wang, K.-X., 2010, "Borehole Guided Waves in a Non-Newtonian (Maxwell) Fluid-Saturated Porous Medium," Chin. Phys. B, 19, 084301.

http://dx.doi.org/10.1088/1674-1056/19/8/084301

Djukic, D.S., 1974, "Hiemenz Magnetic Flow of Power-Law Fluids," ASME J. appl. Mech., 41, 822-823.

http://dx.doi.org/10.1115/1.3423405

Dorier, C., and Tichy, J., 1992, "Behavior of a Bingham-Like Viscous Fluid in Lubrication Flows," J. Non-Newtonian Fluid Mech., 45, 291310. http://dx.doi.org/10.1016/0377-0257(92)80065-6

Fan, T., Xu, H., and Pop, I., 2010, "Unsteady Stagnation Flow and Heat Transfer Towards a Shrinking Sheet," Int. Commun. Heat Mass Transfer, 37, 1440-1446.

http://dx.doi.org/10.1016/J.Icheatmasstransfer.2010.08.002

Fang, T., and Zhang, J., 2009, "Closed-Form Exact Solution of MHD Viscous Flow over a Shrinking Sheet," Commun. Nonlinear Sci. Numer. Simulat., 14, 2853-2857.

http://dx.doi.org/10.1016/J.Cnsns.2008.10.005

Fang, T., Zhang, J., and Yao, S., 2009, "Viscous Flow over an Unsteady Shrinking Sheet with Mass Transfer," Chin. Phys. Lett., 26, 014703.

http://dx.doi.org/10.1088/0256-307X/26/1/014703

Fang, T., Zhang, J., and Yao, S., 2010, "Slip Magnetohydrodynamic Viscous Flow over a Permeable Shrinking Sheet," Chin. Phys. Lett., 27, 124702 .

http://dx.doi.org/10.1088/0256-307X/27/12/124702

Fang, T., Tao, H., and Zhong, Y.F., 2012, "Non-Newtonian Power-Law Fluid Flow over a Shrinking Sheet," Chin. Phys. Lett., 29, 114703. http://dx.doi.org/10.1088/0256-307X/29/11/114703

Fox, V.G, Erickson, L.E., and Fan, L.T., 1969, “The Laminar Boundary Layer on a Moving Continuous Flat Sheet Immersed in a NonNewtonian Fluid," AIChE J., 15, 327-333. 


\section{http://dx.doi.org/10.1002/Aic.690150307}

Fredrickson, A.G., 1964, Principles and applications of Rheology, Prentice-Hall, Englewood Cliffs, N.J.

Goldstein, S., 1965, "On Backward Boundary Layers and Flow in Converging Passages,” J. Fluid Mech., 21, 33-45.

http://dx.doi.org/10.1017/S0022112065000034

Hayat, T., Sajid, M., and Pop, I., 2008a, "Three-Dimensional Flow over a Stretching Surface in a Viscoelastic Fluid," Nonlinear Anal. Real World appl., 9, 1811-1822. http://dx.doi.org/10.1016/J.NonrwA.2007.05.010

Hayat, T., abbas, Z., and ali, N., 2008b, "MHD Flow and Mass Transfer of a Upper-Convected Maxwell Fluid Past a Porous Shrinking Sheet with Chemical Reaction Species," Phys. Lett. a, 372, 4698-4704. http://dx.doi.org/10.1016/J.PhysletA.2008.05.006

Hayat, T., Iram, S., Javed, T., and asghar, S., 2010, "Shrinking Flow of Second Grade Fluid in a Rotating Frame: an analytic Solution," Commun. Nonlinear Sci. Numer. Simulat., 15, 2932-2941.

http://dx.doi.org/10.1016/J.Cnsns.2009.11.030

Hayat, T., Shehzad, S.A., alsaedi, A., alhothuali, M.S., 2012, "Mixed Convection Stagnation Point Flow of Casson Fluid with Convective Boundary Conditions," Chin. Phys. Lett., 29, 114704. http://dx.doi.org/10.1088/0256-307X/29/11/114704

Hiemenz, K., 1911, "Die Grenzschicht an Einem in Den Gleichformingen Flussigkeits-Strom Einge-Tauchten Graden Kreiszylinder," Dingler's Poly. J., 326, 321-324.

Ishak, A., Lok, Y.Y., and Pop, I., 2010, "Stagnation-Point Flow over a Shrinking Sheet in a Micropolar Fluid," Chem. Eng. Commun., 197, 1417-1427.

http://dx.doi.org/10.1080/00986441003626169

Layek, G.C., Mukhopadhyay, S., and Samad Sk.A., 2007, "Heat and Mass Transfer analysis For Boundary Layer Stagnation-Point Flow towards a Heated Porous Stretching Sheet with Heat absorption/Generation and Suction/Blowing," IntCommun. Heat Mass Transfer, 34, 347-356.

http://dx.doi.org/10.1016/J.Icheatmasstransfer.2006.11.011

Khan, Y., Hussain, A., and Faraz, N., 2012, "Unsteady Linear Viscoelastic Fluid Model over a Stretching/Shrinking Sheet in The Region of Stagnation Point Flows," Sci. Iran., 19, 1541-1549.

http://dx.doi.org/10.1016/J.Scient.2012.10.019

Lok, Y.Y., Ishak, A., and Pop, I., 2011, "MHD Stagnation-Point Flow Towards a Shrinking Sheet," Int. J. Numer. Meth. Heat Fluid Flow, 21, 61-72.

http://dx.doi.org/10.1108/09615531111095076

Mahapatra, T.R., and Gupta, A.S., 2001, "Magnetohydrodynamic Stagnation-Point Flow Towards a Stretching Sheet," Acta Mech., 152, 191-196.

http://dx.doi.org/10.1007/BF01176953

Mahapatra, T.R., Nandy, S,K., and Gupta, a,S., 2009, "Magnetohydrodynamic Stagnation-Point Flow of a Power-Law Fluid Towards a Stretching Surface," Int. J. Non-Linear Mech., 44, 124-129. http://dx.doi.org/ 10.1016/J.Ijnonlinmec.2008.09.005

Mahapatra, T.R., Nandy, S.K., and Gupta, A.S., 2011, "Momentum and Heat Transfer in MHD Stagnation-Point Flow over a Shrinking Sheet," aSME J appl. Mech., 78, 021015.

http://dx.doi.org/10.1115/1.4002577

Mahapatra, T.R., Nandy, S.K., and Gupta, A.S., 2012, "Oblique Stagnation-Point Flow and Heat Transfer Towards a Shrinking Sheet with Thermal Radiation," Meccanica, 47, 1325-1335.

http://dx.doi.org/10.1007/S11012-011-9516-Z
Mahapatra, T.R., and Nandy, S.K., 2013, "Stability of Dual Solutions in Stagnation-Point Flow and Heat Transfer over a Porous Shrinking Sheet with Thermal Radiation," Meccanica, 48, 23-32.

http://dx.doi.org/10.1007/S11012-012-9579-5

Miklavčič, M., and Wang, C.Y., 2006, "Viscous Flow Due a Shrinking Sheet," Q. appl. Math., 64, 283-290.

http://dx.doi.org/10.1090/S0033-569X-06-01002-5

Mustafa, M., Hayat, T., Pop, I. and aziz, A., 2011, "Unsteady Boundary Layer Flow of a Casson Fluid Due To an Impulsively Started Moving Flat Plate," Heat Transfer asian Res., 40, 563-576.

http://dx.doi.org/10.1002/Htj.20358

Nadeem, S., Hussain, A., and Khan, M., 2010, "HAM Solutions For Boundary Layer Flow in The Region of The Stagnation Point Towards a Stretching Sheet," Commun. Nonlinear Sci. Numer. Simulat., 15, 475481.

http://dx.doi.org/10.1016/J.Cnsns.2009.04.037

Nakamura, M., and Sawada, T., 1988, "Numerical Study On The Flow of a Non-Newtonian Fluid Through an axisymmetric Stenosis," aSME J. Biomechanical Eng., 110, 137-143.

http://dx.doi.org/10.1115/1.3108418

Nazar, R., amin, N., Filip, D., and Pop, I., 2004, "Unsteady Boundary Layer Flow in The Region of The Stagnation Point On a Stretching Sheet," Int. J. Eng. Sci., 42, 1241-1253. http://dx.doi.org/10.1016/J.Ijengsci.2003.12.002

Nazar, R., Jaradat, M., arifin, N.M., and Pop, I., 2011, "StagnationPoint Flow Past a Shrinking Sheet in a Nanofluid," Cent. Eur. J. Phys., 9, 1195-1202.

http://dx.doi.org/10.2478/S11534-011-0024-5

Rajagopal, K.R., 1980, "Viscometric Flows of Third Grade Fluids," Mech. Res. Commun., 7, 21-25.

http://dx.doi.org/ 10.1016/0093-6413(80)90020-8

Rajagopal, K.R., and Gupta A.S., 1981, "On a Class of Exact Solutions To The Equations of Motion of a Second Grade Fluid," Int. J. Eng. Sci., 19, 1009-1014.

http://dx.doi.org/10.1016/0020-7225(81)90135-X

Rajagopal, K.R., Na, T.Y., and Gupta, A.S., 1984, "Flow of Viscoelastic Fluid over a Stretching Sheet," Rheol. acta, 23, 213-215. http://dx.doi.org/10.1007/BF01332078

Rosali, H., Ishak, A., Pop, I., 2011, "Stagnation Point Flow and Heat Transfer over a Stretching/Shrinking Sheet in a Porous Medium," IntCommun. Heat Mass Transfer, 38, 1029-1032. http://dx.doi.org/10.1016/J.Icheatmasstransfer.2011.04.031

Salem, A,M., and Fathy, R., 2012, "Effects of Variable Properties On MHD Heat and Mass Transfer Flow Near a Stagnation Point Towards a Stretching Sheet in a Porous Medium with Thermal Radiation," Chin. Phys. B, 21, 054701.

http://dx.doi.org/10.1088/1674-1056/21/5/054701

Sankara, K.K., and Watson, L.T., 1985, "Micropolar Flow Past a Stretching Sheet," Z. angew. Math. Phys., 36, 845-853. http://dx.doi.org/10.1007/BF00944898

Schlichting, H., and Gersten, K., 2000, Boundary Layer Theory, Springer, Berlin.

Siddappa, B., and Abel, M.S., 1985, "Non-Newtonian Flow past a Stretching Plate,” Z. Angew. Math. Phys., 36, 890-892.

http://dx.doi.org/10.1007/BF00944900

Troy, W.C., Overman, E.A., Ermentrout, H.G.B., and Keerner, J.P., 1987, "Uniqueness of the Flow of a Second Order Fluid past a Stretching Sheet," Quart. appl. Math., 44, 753-755.

MR 872826 (87m:76009) 
Van Gorder, R.A., and Vajravelu, K., 2010, "Hydromagnetic Stagnation Point Flow of a Second Grade Fluid over a Stretching Sheet," Mech. Res. Commun., 37, 113-118.

http://dx.doi.org/10.1016/J.Mechrescom.2009.09.009

Van Gorder, R.A., Vajravelu, K., and Pop, I., 2012, "Hydromagnetic Stagnation Point Flow of a Viscous Fluid over a Stretching Or Shrinking Sheet," Meccanica, 47, 31-50.

http://dx.doi.org/10.1007/S11012-010-9402-0

Wang, C.Y., 1990, "Liquid Film on an Unsteady Stretching Sheet," $Q$. Appl. Math., 48, 601-610.

Wang, C.Y., 2008, "Stagnation Flow towards a Shrinking Sheet," Int. J. Non-Linear Mech., 43, 377-382.
http://dx.doi.org/10.1016/J.Ijnonlinmec.2007.12.021

Wilkinson, W., 1970, "The Drainage of a Maxwell Liquid Down a Vertical Plate," Chem. Eng. J., 1, 255-257. http://dx.doi.org/10.1016/0300-9467(70)80008-9

Yacob, N.A., Ishak, A., and Pop, I., 2011, "Melting Heat Transfer in Boundary Layer Stagnation-Point Flow Towards a Stretching/Shrinking Sheet in a Micropolar Fluid," Comput. Fluids, 47, 16-21. http://dx.doi.org/10.1016/J.Compfluid.2011.01.040

Zhou, X.-F., and Gao L., 2007, "Effect of Multipolar interaction on The Effective Thermal Conductivity of Nanofluids," Chin. Phys. B, 16, 2028-2032.

http://dx.doi.org/10.1088/1009-1963/16/7/037 